\title{
Mapping Case Studies of Public Engagement and Participation in Science and Technology
}

\author{
Paulo Maia de Loureiro \\ IN+ Center for Innovation Technology and Policy Research, Instituto Superior Técnico, Universidade de \\ Lisboa, Portugal/p.maia@tecnico.ulisboa.pt
}

Hugo Horta

Social Contexts and Policies of Education, Faculty of Education, The University of Hong Kong, China

\section{João M. Santos'}

Centro de Investigação e Estudos de Sociologia (CIES-IUL), Instituto Universitário de Lisboa (ISCTE-IUL), Portugal

\begin{abstract}
In recent years, increasing criticism has been levelled against case study based research on public engagement and participation in science and technology (PEST). Most critics argue that such case studies are highly contextual and fail to provide global, holistic and systemic views of public engagement phenomena. In this study, we mapped the case study literature on PEST by identifying a robust sample of articles, and analysed it looking for emerging patterns that could provide empirical evidence for new frameworks of public engagement design and analysis. Results show that the case study based literature on PEST continues to grow, although concentrated in a few countries and knowledge domains. The trends that emerged from the sample reveal high centralisation and planning and suggest that deficit science communication models are still common. We argue that future frameworks may focus on decentralising hierarchical power and dependency relationships between agents.
\end{abstract}

Keywords: case study research, public engagement, public participation, science and technology, knowledge mapping, science communication

\section{Introduction}

The case study literature on public engagement and participation in science and technology (PEST) has recently become a subject of increasing criticism. In general terms, most critiques argue that case studies only produce micro-level insights and fail to provide global, systemic or holistic views of participatory phenomena (Braun and Könninger, 2018). The body of literature that is being criticized emerged in the early 2000s under the name of the 'participatory turn' (Cass, 
2006; Jasanoff, 2003), which called for greater involvement of the public in science and technology governance and decision-making in response to the flaws of the then widespread deficit model of science communication.

The deficit model had greater prominence between the 1960s and the 1990s, and aimed to quantify and improve the public's scientific literacy. It can be defined as top-down "one-way communication from experts with knowledge to publics without it" (Trench, 2008: 119). Experts are not only scientists but also policy makers, science managers and science communicators who plan and provide the means to inform and educate the public in a one-way top-down manner. But this model began to be questioned by scholars who argue that science has deeper political, economic and regulatory implications, and that the public's views should be incorporated into decision-making processes. This critical perspective proposing a participatory model is also known as contextualism (Sturgis and Allum, 2004). From this perspective, a consensus emerged that 'public engagement with science and technology' refers to practices involving lay people, scientists, policy makers and a variety of other social actors interacting with each other to integrate a wider range of views on science governance (Rowe and Frewer, 2004).

The theoretical paradigm shift from the deficit model to the participatory models also implied methodological changes in public engagement studies, from survey-based quantitative measurements to qualitative methods that would capture the social context of participation (Wynne, 1992). Since then, case study research followed by critical assessment has become the most widely applied practice in PEST studies (Irwin et al., 2013; Sturgis and Allum, 2004).

Case studies of public engagement provide contextual results based on specific details. Bensaude-Vincent (2014) suggests that from a linguistic perspective, 'public engagement' is a buzzword coming from official science policy bodies, and therefore the operationalisation of the concept in different social settings may explain some discrepancies between the signifier and the signified. In a cross-analysis of the UK and the US, Jasanoff (2005a) argues that all publics are different in that they are motivated by culturally determined 'civic epistemologies' and each democratic structure generates specific engagement strategies (Jasanoff, 2005b). Similarly, Nowotny (2014) suggests that publics are defined by political and cultural collective imaginaries that largely emerge from the interaction of citizens with the new media. Other studies focused on publics' attitudes towards science (Allum et al., 2008; Callon, 1999; Castell et al., 2014) support the idea that different social contexts produce different outcomes in participatory processes.

In other words, the interaction between agents involved in participatory processes, as well as the outcome of each case, is significantly determined by cultural, social, political and scientific factors that may vary from region to region. In this sense, multiple models of participation and engagement processes arise as a response to different patterns of social activity. However, this trend brings other problems. Irwin et al. (2013) point out that case studies and critical assessments frustrate policy makers as they are always in the critical eye of social scientists; and Stilgoe et al. (2014: 6) go further by proposing that the literature may be turning into a never-ending "litany of engagement case studies and evaluations" in need of new research strategies that point to the "broader project of dialogic governance". Braun and Könninger (2018) suggest that researchers' focus may shift from the evaluation of isolated case studies towards a wider inquiry that includes a large share of contextual forms of engagement. However, these claims are conjectural and lack empirical evidence.

Aligned with this wave of critical views is the growing idea of a 'systemic turn' emerging in deliberative democracy studies (Curato and Böker, 2016; Ercan et al., 2017; Owen and Smith, 2015) and studies of participation in socio-technical change (Chilvers et al., 2018; Macnaghten and Chilvers, 2014) that investigate how participation interconnects in wider systems. Despite criticism to case study research, we believe that case studies still bring in-depth and detailed information of the subjects under study, but on the other hand we acknowledge the potential rewards of a systemic view of participatory phenomena. 
In our study we create a map of the case study literature of PEST and draw systemic patterns from it. Analysis of systemic patterns deliver key map features and provides strong evidence of shared practices across isolated cases, regardless of their context. In this sense, this research provides empirical evidence for the design of general frameworks and may guide future case studies. The analysis used a set of articles published in the international indexed literature, which were analysed in three stages using different methodologies from scientometric studies focused on disciplinary-based or theme-based mapping analyses (e.g. Zheng et al., 2015). First, descriptive statistics and trend analysis were implemented to show the country distribution of the production of PEST literature based on case studies. Second, cross-country network analysis of the sample was conducted to identify and analyse the main academic communities involved in the PEST literature using case studies. Third, using text-mining tools and text analysis strategies, we sought evidence of common language patterns throughout the sample, and also within each academic community. From the combination of these methods, we not only deliver a broad understanding from isolated contextual and expectedly unrelated case studies, but also outline the landscape of the public engagement and participation case study literature, which may serve as a tool for future studies.

\section{Data and Methods}

\section{Data}

This study draws on the Scopus database, one of the largest abstract and citation indices of international peer-reviewed research literature, frequently used in studies focused on mapping thematic areas and fields of knowledge (VegaAlmeida et al., 2018). Scopus was chosen as the literature index platform for this analysis for a number of reasons. Compared with other indexing platforms such as Clarivate Web of Science, Scopus has better coverage of publications in the social sciences and health sciences, and also of journals covering multidisciplinary and emergent research approaches, such as the ones covered by the present study (Mongeon and Paul-Hus, 2016).
Additionally, although the high correlation of Scopus and Web of Science data makes either an acceptable choice in principle (Archambault et al., 2009), studies have shown that Scopus has fewer inconsistencies and errors than other publication indexing platforms, indicating that Scopus yields more reliable findings (Adriaanse and Rensleigh, 2013).

The data were extracted in July 2018 and further verified at later dates for the sake of reliability and consistency. We selected all articles published from 2002 to 2017 that were returned after a Boolean search of the words or a combination of the words 'public engagement' or 'public participation', and 'case study' or 'case studies' in the title, abstracts, and keywords. This permitted the identification of publications focused on public engagement and/or participation in science and technology that used 'case studies' as the main or one of the core methodologies of analysis, consonant with the purpose of the research question in this study. The decision to set the extraction from 2002 was based on the shift identified in the scientific and research environment that called for a new relationship between science and society (Chopyak and Levesque, 2002) and which became known as the 'participatory turn'(Jasanoff, 2003). The 2017 end date coincides with the rise of criticism aimed at the participatory model and mostly with the emergence of a wave of articles that discuss the beginning of a 'systemic turn' in public participation. This exercise led to the identification of 855 articles. To avoid duplicated publications and ensure that the publications under analysis were relevant to our study purpose, all of the publications were read by the authors, which led to 437 publications being filtered out. This was in accordance with best practice in this type of analysis for ensuring the validity and reliability of the sample (Horta and Jung, 2014). The final sample of publications was composed of 418 articles from the PEST literature published between 2002 and 2017 that included case studies.

\section{Methods}

The analysis of the data involved three complementary methodologies that provided a comprehensive analysis and mapping of knowledge on 
the topic of public participation in science and technology, based on publications. These were as follows: descriptive statistics and trend analysis, network analysis, and text analysis.

\section{Descriptive statistics and trend analysis}

The analysis of the 418 articles commenced with a presentation of the sample's descriptive statistics, followed by a trend analysis. The purpose was to give a general characterisation and mapping of the topic from both static and dynamic perspectives (e.g. Boyack et al., 2007). The static perspective served to identify the countries and authors that produced the greatest number of publications on the topic, while the coverage of journals and fields of knowledge indicated the extent to which the broad theme of publications on public engagement in science and technology was concentrated or dispersed among journals and fields of knowledge. The dynamic perspective enabled the same type of analysis but in an evolutive way, so that the mapping of the theme could be understood in a temporal dimension. As has been done in other scientometrics studies (see Horta, 2018) the dynamic perspective was provided on a quinquennial basis (5-year periods) to mitigate yearly or short-term fluctuations, thus preserving the analytical value of the general trend without adversely affecting it.

\section{Network analysis}

The publications and their relevant metadata were converted into a country-based nodes and edges dataset using the Table2Net tool. The resulting dataset contained 57 nodes linked by 131 edges, in which a node represented a country and an edge represented a collaborative venture between two countries. This allowed the dataset to be imported into Gephi, a social network analysis software package, whose use is increasingly common in bibliometric studies to analyse coauthor and co-citation networks (Horta and Jung, 2014). On the Gephi working platform, the Giant Component filter was applied to the network to filter out isolated nodes that were not part of the main structure. This reduced the number of visible nodes to 42 and edges to 130 . Then, we used Gephi's clustering/community algorithm based on the Louvain method to identify collaborative communities within the sample. This algorithm permits the identification of communities as sets of interconnected modes though a three-stage modularization process that is recognized for its high optimization accuracy (Blondel et al., 2008). In addition, network centrality measures were computed namely, average degree and betweenness centrality to identify the countries with the greatest influence and impact on the network.

\section{Text analysis}

The aim of the text analysis was to find linguistic patterns within the sample. To that end, we sought to emulate the network in sets of articles representing its entirety, as well as the identified collaboration communities. Through this exercise, our intention was to perceive the main discursive trends of case studies on public participation in science and technology, and also to examine any significant discursive variations between communities. First, the articles corresponding to the isolated countries were removed from the sample with the Giant Component filter in the network analysis, leaving 379 articles that were uploaded to the Nvivo text analysis tool.

Each article was assigned one or more countries, according to the authors' affiliations. Then, the text of each article was coded, generally starting at the beginning of the introduction section and ending at the end of the conclusion; that is, the abstract, keywords and the list of bibliographic references were all excluded from the coding, as these parts of an article, having different objectives, show different linguistic traits that could interfere with the results (Loureiro and Conceição, 2019; Samraj, 2005). Non-scientific content, such as declarations of interests and acknowledgments, was not coded.

After the coding process, stemmed words such as 'environment', 'environments', 'environmental' and 'environmentally' were clustered into the same group of meaning. Additionally, some words were removed for the word frequency analysis according to the following criteria: (1) expected buzzwords, such as the terms of the sample definition, e.g. 'public', 'participation', 'engagement', 'case' and 'study'; (2) words from which it is not possible to derive special contextual meaning, such as 'make,' 'use,' 'also'; and (3) stopwords, such as 'or,' 'then,',of', 'and', 'if', which were removed automatically by the software. The elimination of these 
words aimed at decreasing the residual effect of any result extracted from the sample.

Different techniques of text analysis were implemented: word frequency ranking, which lists the most frequent words or concepts within the coded text; comparative analysis of word frequency ranks in the different subsets of the sample, looking for language variations between them; and collocation analysis, which correlates the use of two or more words within the sample. Furthermore, semantic categorisation and analysis were implemented to enable the results to be read in the context of the debate on public engagement and participation in science and technology.

\section{Results and Discussion}

\section{Geographic distribution}

Statistical analysis of the bibliometric data of the sample showed that productivity in this area was increasing, particularly in Europe, North America and Asia since 2014 (Figure 1). The geographic distribution of the publications, based on total counts of the authors' country affiliations (548), demonstrated that the concentration was mainly in Europe (278) and in North America (135), followed by Asia (68), Oceania (44), South and Cen- tral America (12) and Africa (11). Notably, the knowledge produced on the topic seemed to be increasingly driven by Europe-affiliated researchers, which in the last quinquennium produced almost half of the total of publications on PEST that used case studies as their main or one of their core methodologies (48\%). However, the regions of the world with the highest compound annual growth rates in the time period under analysis were Oceania and Asia, both starting with very low output values. Europe's compound growth rate was higher than that of North America. African and South and Central America production on this theme was residual. Their production in the last quinquennium represented less than half and around one third of the production in North America and Europe, respectively, in the initial quinquennium. These findings are in alignment with regional shares of global knowledge output (King, 2004).

From a country aggregate perspective, there was a high concentration of publications in English native-speaking countries such as the UK (90) and the USA (86), followed by Canada (49) and Australia (41). These countries have scientific prominence worldwide as major producers of knowledge; they also have large populations

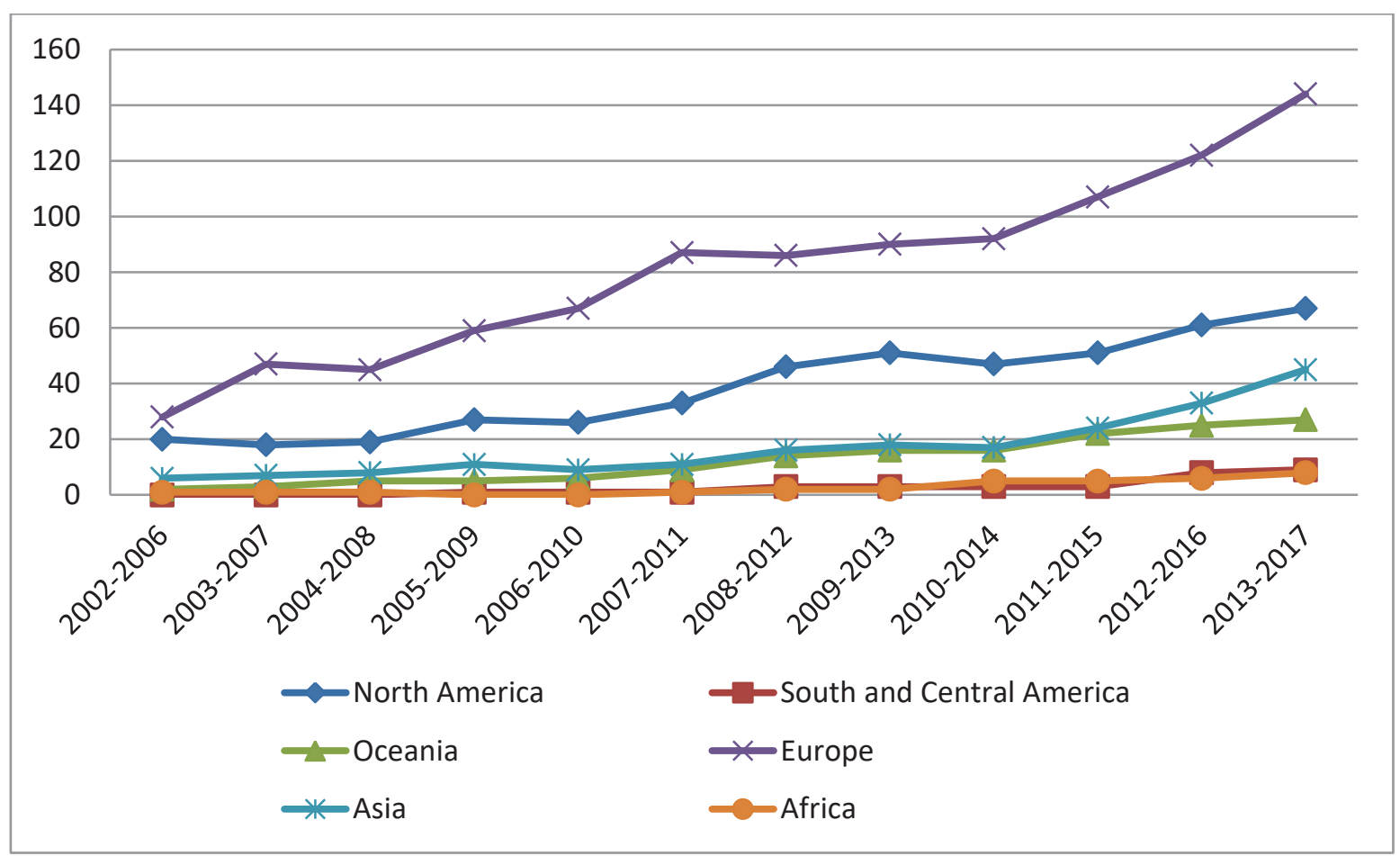

Figure 1. Evolution of publications on the topic of public participation and engagement in science and technology. 
and strong economies. Still, in the range of 10 to 30 publications produced during the timeframe under analysis, other countries and jurisdictions such as the Netherlands (29), Italy (19), China (18), Germany (17), Denmark (16), Portugal (13), Sweden (13), Switzerland (12), Hong Kong (10) and Spain (10), also had a significant role. The countries above accounted for $77 \%$ of the literature produced. All the remaining publications were scattered across 43 countries.

The greater concentration of publications in native English-speaking countries, particularly in the UK and USA, may be initially explained by the fact that these countries are leaders in the publication of academic documents in the social sciences (Mosbah-Natanson and Gingras, 2014). Although the overall production of social sciences in the US is larger than that in the UK, our sample showed that the UK had about the same productivity as the USA in the PEST literature using case studies. This high productivity in the UK may also be related to the incentives that science funding agencies have given research institutions in recent years to capture the impact of science through case studies, as described by Van Noorden (2015). This is also aligned with the fact that since 1985 the Royal Society has taken a clear position to encourage the engagement of science with society (Royal Society, 1985), which gave rise to the academic movement known as 'The Public Understanding of science' (Miller, 1992; Thomas and Durant, 1987). Furthermore, as a member state of the European Union, the UK was subject to the European science funding framework calling for science and innovation to address the values, needs and expectations of society through multi-stakeholder and public engagement (European Commission, 2014; Owen et al., 2012). On the other hand, the lower relative productivity of the USA, when compared to the UK, may be due to the fact that the rules and incentives created to bring science and society together, such as the Broder Impacts programme of the National Science Foundation (which was roughly adopted by other funding institutions like the National Institutes of Health, and the Bill \& Melinda Gates Foundation, using social impact criteria in the evaluation of research projects funding proposals), encountered internal resist- ance (Holbrook, 2005). Furthermore, they also seem to have a discourse more oriented towards the benefit of science, technology, engineering and mathematics, while societal benefit is considered as a natural consequence of the programme rather than a goal (Davis and Laas, 2014).

The idea that some countries are more prone to studying participatory phenomena than others, and that the geographic distribution of publications does not depend exclusively on the total volume of academic output, was underlined by some concentration of this production in less well-ranked countries, such as Denmark and Portugal. Taking the latter country as an example, the national strategy for science that has been implemented since the mid-1990s, based on the renewal of science education, the fostering of scientific culture and the opening of science to society (Gago, 1990, 1991) may well explain the results obtained by our study. The reverse was also true, as some well-ranked countries had very few publications on the topic, such as Japan, India and the Russian Federation. This raises questions about the reasons for the lack of interest in PEST studies in some developed countries. Our intuition leads us to hypothesize that general interest in PEST may be related to civic engagement rates of each country. We compared our results with two civic engagement indexes and found some correlation between interest in the topic and civic engagement rates: Japan, India and the Russian Federation show low rates of civic engagement, but the UK, USA, Australia and the Netherlands, consistently have high rates. But if it is true that civic engagement rates may be related to interest (or lack of interest) in PEST, it also seems to be true that public policies and national long-term strategies may contribute to invert this trend. Again, the case of Portugal is of interest: despite having low rates of civic engagement, the country shows a relatively high concentration of publications of PEST case studies, which may reveal that long-term open science strategies and policies may be a generator of national differences and have a potential impact on academic output. In sum, it seems evident that each country has a specific proclivity to address (or not) case studies of public engagement and participation in science and technology, but the reasons for each one 
remain to be determined and should be studied individually in more depth.

\section{Country based network}

A social network was created to map and visualise the structure of international collaboration (i.e., coauthorship) between countries within the sample. The aim was to identify local and global patterns of activity in the form of communities, as well as to locate the most influential countries in the network. We began by computing the modularity of the network with a resolution limit adjusted to 1.2. Modularity is primarily used to reduce the complexity of a network by dividing it into communities. It is represented on a scale between -1 and 1 , and measures the density of links within communities as opposed to links between communities (Blondel et al., 2008). Positive values suggest the presence of community structures (Newman, 2006) and values higher than 0.3 are clear indicators of community within the network (Fortunato and Barthélemy, 2007: 37). The resolution limits of modularity determine the level of detail of the communities; that is, lower resolution values tend to identify a greater number of small communities, and higher resolution values identify fewer but larger communities. The resolution limit was set to 1.2 so that the resulting communities would present a clear modularity value above 0.3.

The results yielded three distinct communities with a modularity value of 0.424 . The nodes were colour-coded to visually identify each community (Figure 2). The analysis proceeded with social network statistics. First, we computed the average degree, which represents the average number of edges connected to each node. This returned a value of 3.095 indicating that each country was on average connected to approximately three other countries. In Figure 2, the size of the nodes is defined according to the average degree of each country, where larger nodes represent countries with more international connections. In this figure, the dominance of native English-speaking countries is conspicuous. Next, we calculated betweenness centrality (Brandes, 2001), which is measured by the number of times a node is located in the shortest path between two nodes. High betweenness indicates the most central and

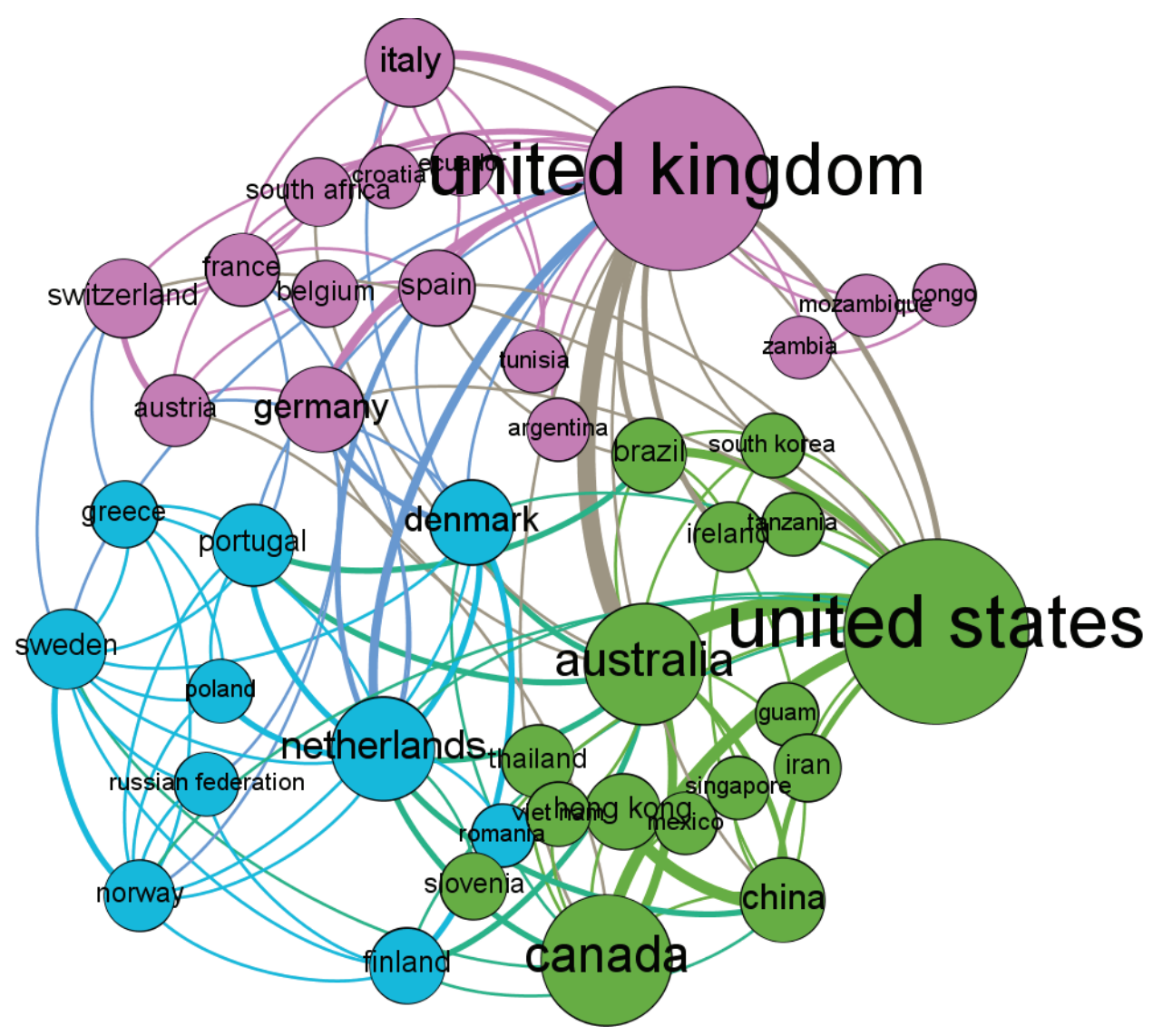

Figure 2. Co-authorship community clustering and networking of countries. 
influential nodes in the network. The countries with the highest betweenness centrality values were the UK (274.6), the USA (183.8) and the Netherlands (104.6). Each of these countries was also the most central in each one of the identified communities.

The purple community gravitated around the UK and was mostly composed of European countries, namely Italy, Germany, Switzerland, Spain, Belgium, Austria, France and Croatia. In this community, although with less influence, were African countries such as South Africa, Tunisia, Zambia, Mozambique and Congo, but also Argentina and Ecuador from South and Central America. In the green community, set around the USA, Australia and Canada also stood out, with high average degrees. Out of the three communities identified in the sample, this one stood out for greater range and global distribution in that all of the continents were represented, with particular emphasis on the number of Asian countries and jurisdictions such as Thailand, Vietnam, South Korea, China, Hong Kong, Singapore and Iran. From Europe were Slovenia and Ireland, from South and Central America were Brazil and Mexico, and from Africa was Tanzania. The blue community was centred on the Netherlands and was composed entirely of European countries, namely Denmark, Portugal, Sweden, Finland, Norway, Greece, Romania, Poland and the Russian Federation.

The purple community gravitated around the UK and was mostly composed of European countries, namely Italy, Germany, Switzerland, Spain, Belgium, Austria, France and Croatia. In this community, although with less influence, were African countries such as South Africa, Tunisia, Zambia, Mozambique and Congo, but also Argentina and Ecuador from South and Central America. In the green community, set around the USA, Australia and Canada also stood out, with high average degrees. Out of the three communities identified in the sample, this one stood out for greater range and global distribution in that all of the continents were represented, with particular emphasis on the number of Asian countries and jurisdictions such as Thailand, Vietnam, South Korea, China, Hong Kong, Singapore and Iran. From Europe were Slovenia and Ireland, from
South and Central America were Brazil and Mexico, and from Africa was Tanzania. The blue community was centred on the Netherlands and was composed entirely of European countries, namely Denmark, Portugal, Sweden, Finland, Norway, Greece, Romania, Poland and the Russian Federation.

The causes underlying the formation of these country clusters are not explicit in these measurements and can be multiple, from researchers' affinity for specific phenomena in the form of pre-existing research networks to the impact of academic mobility protocols signed between countries or research institutions that may contribute to the arrangement of collaborations among authors (Bhattacharya et al., 2015; Patrício et al., 2018). For the purple and green community clusters, formed around the UK and the US respectively, path dependence seems to be a highly plausible cause, as both the UK and the US are pioneers in engaging the public in science policy. Historically, the relationship between science and the public has been deeply rooted within these countries' democratic cultures, notably through the endeavours of the Royal Society in the UK and both the American Association for the Advancement of Science and the National Science Foundation in the US. These institutions, among others, have been recognized over time for advocating and implementing broader processes for integrating society into science such as: funding research in the fields of science and society; developing studies on the public's ability to understand science and participate in science policy and decision making; and creating modern, interactive and educational science museums in which the public shifts from mere spectators to active participants, see e.g. (Besley et al., 2013; Haberer, 1983; Miller, 1992; Rennie and McClafferty, 1996; Royal Society, 1985; Thomas and Durant, 1987). The blue community revolved around the Netherlands, as the most influential country with the highest betweenness centrality values. Along with the UK, the Netherlands is a leading country in Europe in terms of promoting public engagement with science; this is where the concept of Responsible Research and Innovation emerged in the 2000s (Rip, 2014; Stahl, 2013). Responsible Research and Innovation was later implemented in 2014 
Table 1. Journals with the highest number of publications on the topic of public participation and engagement in science and technology.

\begin{tabular}{|l|c|}
\hline Journal & No. of publications \\
\hline Journal of Environmental Planning and Management & 11 \\
\hline Land Use Policy & 10 \\
\hline Public Understanding of Science & 10 \\
\hline Local Environment & 9 \\
\hline Ecology and Society & 7 \\
\hline Energy Policy & 7 \\
\hline Environmental Management & 7 \\
\hline Journal of Environmental Assessment Policy and Management & 6 \\
\hline Journal of Environmental Management & 6 \\
\hline Journal of Science Communication & 6 \\
\hline Society and Natural Resources & 6 \\
\hline Environmental Impact Assessment Review & 6 \\
\hline Environmental Science and Policy & 5 \\
\hline Journal of the American Water Resources Association & 5 \\
\hline
\end{tabular}

as a science-funding framework of the European Union, calling for broader public involvement in science. This may well explain the fact that this community consists of European countries only.

\section{Journals and research fields}

All 418 articles were distributed among 249 journals, of which 185 journals had one single publication, and only 14 journals had 5 or more publications referring to the PEST literature using case studies (Table 1). This indicates a very low concentration of publications (with an approximate average of 1.6 articles per journal), compared, for example, with publications on industrial wastewater research (Zheng et al., 2015). The small concentration in few journals can be interpreted as a sign of an emerging topic in the academic literature, but may also indicate a topic that is multidisciplinary and of interest to researchers from different fields of knowledge, similar to the case of higher education studies (Horta and Jung, 2014). It seems likely that the explanation encompasses both rationales simultaneously, because some of the journals that publish most on the topic are devoted, to a large extent, to the study of the social phenomena of public engagement with science and technology, such as Public Understanding of Science and the Journal of Sci- ence Communication, while others are dedicated to varied fields of knowledge with high levels of public interest and, therefore, participation.

The scattered distribution of the articles across many journals was not matched by a scattered distribution across fields of knowledge, as one might intuitively expect. ${ }^{1}$ Bibliometric data showed that the social sciences and the environmental sciences were the most significant fields of knowledge in the sample, with 241 and 238 publications respectively (Table 2 ). It was unsurprising to find the social sciences at the top of the fields list, partly because of the social nature of public engagement and participation processes, but also because case studies are research methods specially applied by social scientists (Yin, 2014) but iterative process." This statement is supported by a visual which is displayed on the first page of each chapter. Each chapter contains one step in the linear process of case design (planning, designing, preparing, collecting, analyzing, and sharing. The expectation that the environmental sciences would assume a prominent place in the fields list was also met. It stresses the growing inter and multidisciplinary focus of environmental research as it faces complex challenges that derive from human behaviour and interactions with the natural environment (Virapongse et al., 2016). 
Table 2. Distribution of journals with publications on the topic of public participation and engagement in science and technology by field of knowledge.

\begin{tabular}{|l|c|}
\hline Journal Field of Knowledge & No. of publications \\
\hline Social Sciences & 241 \\
\hline Environmental Science & 238 \\
\hline Agricultural and Biological Sciences & 60 \\
\hline Engineering & 37 \\
\hline Earth and Planetary Sciences & 35 \\
\hline Business, Management and Accounting & 30 \\
\hline Energy & 30 \\
\hline Medicine & 30 \\
\hline Arts and Humanities & 29 \\
\hline
\end{tabular}

\section{Most prolific authors}

The figures for the authors of the publications also pointed to a disparity in terms of the authors' participation in the topic using case studies, with only a few dedicated to the topic and publishing frequently and consistently. Of the 1064 authors identified in the sample, 974 had published only one article; 69 authors had published two articles; 15 authors had published 3 articles; 3 authors had published 4 articles; and 3 authors had published 5 articles (Table 3 ). This appears to indicate that the use of case studies tends to be an occasional methodological tool to observe and better understand PEST phenomena. Again, as in the analysis described in the previous section, this suggests an emerging topic in the literature, insofar as research topics often emerge in the social sciences first by the arrival of a large number of case studies, which have a strongly rooted exploratory nature, and are later consolidated into further theoretical foundations and the application of more confirmatory methodologies (Hyett et al., 2014).

Another relevant fact pointing to the emergence of a combination of theme and method is that for all but 1 of the 20 authors, the publications were just a small part of each author's research profile (usually representing around 1 to $10 \%$ of their total publications). Exceptions included Carmel Anderson, whose career publications all focused on case studies on PEST-related issues, and Chutarat Chompunth, for whom case studies represented $33 \%$ of her total publications. This again points to an opportunistic dedication to the topic using case studies, or an interest that is evident but merely part of broader themes and issues rather than a core interest.

As expected, the most prolific authors were based in countries that had the largest production of publications identified in previous sections. However, it was interesting to find in the top five an author based in Thailand, and in the top 10, an author based in Hong Kong. There was also a somewhat surprising lack of prolific authors based in the Netherlands, China, Portugal, Switzerland and Spain, suggesting that the contribution of these countries to this combination of topic and methods is produced by different scholars, not led by a single scholar or group of scholars in particular. A further note of interest is that Australia had the most prolific author (Greg Gordon Brown) and was the only country with three authors in the top 10 for prolificacy. Finally, the profile of the authors was strongly multidisciplinary, with most of the main fields of publication concentrated in the environmental sciences and social sciences.

\section{Discursive patterns}

To better understand the research produced by those case studies on PEST (and possibly identify commonalities or common patterns between communities), we conducted textual analysis to shed light on what has been said in the literature about case studies of public engagement and participation in science and technology. A second purpose was to better understand what was similar and dissimilar in terms of focus and content among the communities identified by 


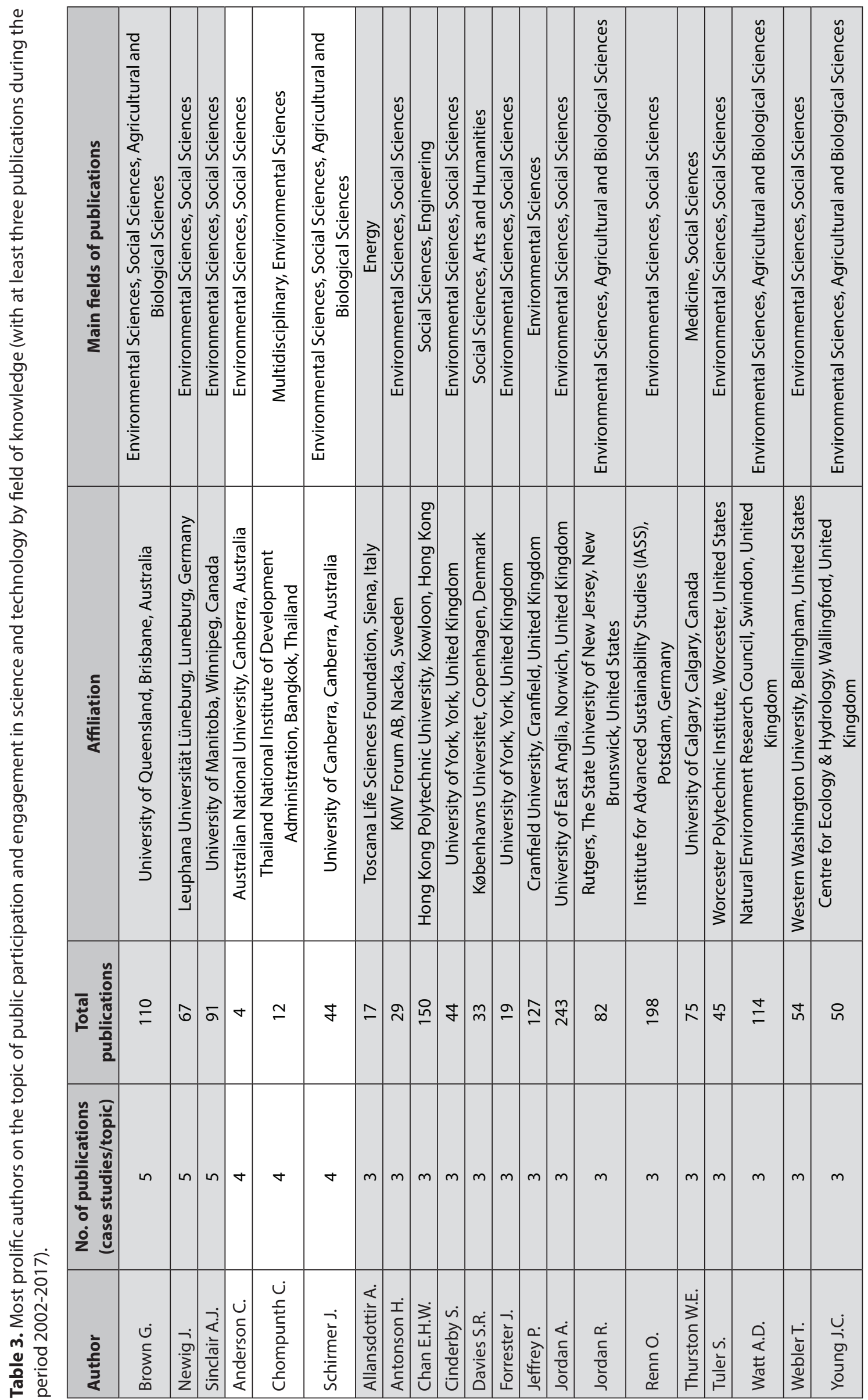


Figure 2. To this end, the sample was divided into subsets of articles to emulate the collaboration network in Figure 2. Word frequency ranks of the full network and of each community were generated. Table 4 shows the 15 most frequent words for each subset and their respective weighted percentages (WP\%). WP\% is the frequency of a given word (including stemmed words) relative to the total number of words counted in the analysis. The results of the word frequency ranks in Table 4 showed that there were no substantial discursive differences among the three communities, as the same words were consistently in the rank of each subset, with very few exceptions. From this we could infer a stable discursive homogeneity across the knowledge produced, regardless differences in the national affiliation of the authors or collaborative groups developing and/or observing case studies of public participation. This lack of diversity may also indicate a state of saturation of the case study literature, as pointed out by critics. However, some differences between the communities emerge if we consider the 30 most frequent words. Possibly, the main difference concerns the disciplinary setting in which public participation is implemented: the word 'forest' only appears in the blue community (ranked 15th), and is mostly used in the context of participatory forest planning; the word 'energy' appears only in the purple commu- nity (ranked 15th), and is collocated with worlds like 'renewable', 'wind', 'geothermal', 'policy', 'systems', 'sources' and 'consumption'; and the word 'land' is limited to the green community (ranked 23rd) and is mostly collocated with (in order of frequency) 'agricultural', 'industrial' and 'urban' land use, management and planning. Other small, but perhaps relevant, differences were found: the blue community is the only one containing the word 'quality' in the ranking (ranked 27th) referring to quality of life, decisions, policy, participation and environment, whereas the purple community placed more emphasis on 'risks' (ranked 27th) in the context of environmental risk assessment, management, governance and mitigation. Finally, the words 'science' and 'responsibility' are present in the purple and green communities (ranked 22nd and 24th, and 24th and 26th respectively) and absent from the blue community. These small differences may indicate a greater tendency towards 'quality' in the European countries in the blue community, while the English-speaking countries that dominate the purple and green communities, appear to have a greater inclination to ethical issues of science focusing the debate on the idea of 'responsibility'.

To complement the analysis of Table 4, discourse analysis was simplified into three distinct semantic fields identified by the results of

Table 4. - Word frequency ranks of the full network and of the three identified communities.

\begin{tabular}{|c|c|c|c|c|c|c|c|c|}
\hline & \multicolumn{2}{|c|}{ Full Network } & \multicolumn{2}{|c|}{ Green Community } & \multicolumn{2}{|c|}{ Purple Community } & \multicolumn{2}{|c|}{ Blue Community } \\
\hline & Word & WP\% & Word & WP\% & Word & WP\% & Word & WP\% \\
\hline 1 & Process & 0.95 & Community & 1.00 & Process & 0.88 & Process & 0.93 \\
\hline 2 & Community & 0.82 & Process & 0.99 & Project & 0.66 & Plan & 0.80 \\
\hline 3 & Plan & 0.70 & Plan & 0.72 & Community & 0.66 & Manage & 0.69 \\
\hline 4 & Project & 0.61 & Information & 0.60 & Local & 0.63 & Stakeholder & 0.67 \\
\hline 5 & Local & 0.58 & Project & 0.55 & Plan & 0.61 & Community & 0.65 \\
\hline 6 & Information & 0.57 & Local & 0.55 & Decision & 0.55 & Local & 0.59 \\
\hline 7 & Manage & 0.53 & Decision & 0.55 & Stakeholder & 0.52 & Information & 0.51 \\
\hline 8 & Decision & 0.52 & Manage & 0.54 & Information & 0.50 & Project & 0.50 \\
\hline 9 & Stakeholder & 0.52 & Govern & 0.50 & Water & 0.49 & Decision & 0.47 \\
\hline 10 & Environment & 0.43 & Environment & 0.46 & Manage & 0.45 & Policy & 0.46 \\
\hline 11 & Govern & 0.43 & Stakeholder & 0.45 & Govern & 0.43 & Citizen & 0.45 \\
\hline 12 & Policy & 0.41 & Policy & 0.39 & Environment & 0.41 & Water & 0.40 \\
\hline 13 & Water & 0.38 & Citizen & 0.39 & Policy & 0.41 & Environment & 0.35 \\
\hline 14 & Citizen & 0.37 & Water & 0.36 & People & 0.34 & Govern & 0.33 \\
\hline 15 & People & 0.32 & People & 0.31 & Energy & 0.31 & Forest & 0.31 \\
\hline
\end{tabular}


Table 5. Semantic Fields based on the results from the frequency ranks analysis.

\begin{tabular}{|c|c|c|}
\hline \multicolumn{2}{|c|}{ Semantic Fields (SFs) } \\
\hline $\begin{array}{c}\text { SF1 Disciplinary context and } \\
\text { research fields }\end{array}$ & SF2 Social setting & $\begin{array}{c}\text { SF3 Organization and } \\
\text { administration }\end{array}$ \\
\hline Environment, Water, Energy, Forest & $\begin{array}{c}\text { Community, Citizen, Local, } \\
\text { Stakeholder, People }\end{array}$ & $\begin{array}{c}\text { Process, Plan, Project, Information, } \\
\text { Manage, Govern, Decision, Policy }\end{array}$ \\
\hline
\end{tabular}

the frequency ranks (see Table 5). Semantic fields are logical generalisations of natural language concepts that are grouped by meaning and used to refer to specific subjects (Akmajian et al., 2010). The first semantic field (SF1) included words related to the disciplinary context and research fields of the case studies under analysis, such as 'environment', 'energy', 'water' and 'forest'. The high frequency of these words confirmed the trend observed in the analysis of journals and research fields, which pointed to a high incidence of environment-related fields of research. SF2 referred to the social settings of the case studies, with words like 'community', 'local', 'stakeholder', 'citizen' and 'people'. The third and largest semantic field (SF3) referred to the organisation and administration of participatory practices, with words like 'process', 'plan', 'project', 'information', 'manage', 'govern', 'decision' and 'policy'.

This analysis, which permitted a closer look at the top of the ranks, showed minor variations between each community. The blue community put more emphasis on the SF3 words ('process', 'plan' and 'manage') than on the SF2 words ('stakeholder', 'community'). The word 'community' was emphasised more in the green community cluster than in any other cluster. Further investigation is needed to understand whether these small changes in rankings are evidence of the emergence of local discursive patterns. In this regard, the words 'process', 'plan' and 'community' were the most noticeable within the full network. To better understand the context of the use of these main words, we implemented collocation analysis, which correlated each of them with other words in the text to provide further contextual meaning (Mello, 2002). The results were delivered in the form of a word tree representing the various contexts in which the word occurred. The results were ordered by the number of matches. Table 6 ranks the higher correlations for the main words 'process, 'plan' and 'community'. The results show the most frequent words in the same sentence at a distance of two words before or after the main word.

Process. The semantic property of the word 'process' refers to a method or way of doing something. In research, it concerns the how rather than the why. The highest correlations with the word 'process' listed in the table fell under semantic fields SF2 and SF3, which meant that case study scholars were mainly focused on how participatory processes work, how they should be managed and how they can assist public policy and decision-making. 'Process' was also strongly correlated with 'plan'.

Table 6. Correlations for the main words 'process, 'plan' and 'community'.

\begin{tabular}{|c|c|c|c|c|c|}
\hline \multicolumn{2}{|c|}{ Process } & \multicolumn{2}{c|}{ Community } & \multicolumn{2}{c|}{ Plan } \\
\hline plan & SF3 & member & SF2 & process & SF3 \\
\hline participation & SF2 & group & SF2 & urban & SF1 \\
\hline consultation & SF2 & local & SF2 & participation & SF2 \\
\hline engagement & SF2 & region & SF2 & manage & SF3 \\
\hline policy & SF3 & engagement & SF2 & collaboration & SF2 \\
\hline decision & SF3 & participation & SF2 & forest & SF1 \\
\hline manage & SF3 & stakeholder & SF2 & decision & SF3 \\
\hline deliberation & SF3 & involvement & SF2 & authority & SF3 \\
\hline
\end{tabular}


Community. The term 'community' was expected to be among the most frequent, given that the main topic of the case studies was the involvement of the public in science and technology decision and policymaking. A community is a group of people in a specific place or united by common interests. The main concepts that emerged from the collocation analysis of the word 'community' were all related to the context or social setting in SF2. These could refer to the agents involved in participation, such as in 'member', 'group' or 'stakeholder', or to the geographical background of the case studies, such as in 'local' and 'region'. Although the terms are somewhat generic and vague, they lead us to the notion of localised context, which has been central to the most recent critiques of the case study literature on public participation.

Plan. In our analysis, the word 'plan' had a more diversified application and was correlated with all the three semantic fields we had defined. 'Urban' planning and 'forest' planning fell under SF1, as they are disciplines that increasingly require public involvement. However, most of their applications were related to SF2 and SF3: collaboration and participation planning, management planning, decision planning and authority planning were some of the main concepts that stood out in the sample. However, the strongest correlation of the term 'plan' was with 'process'. 'Planning process' seemed to be the key concept in the case study PEST literature. To plan is to define in advance a set of actions or intentions in order to control the outcome of those actions. In the context of our object of study, this concept brings us to the notion of centralised organizational structures of public engagement, where institutions in a higher hierarchical position engage the public or other institutions in a top-down manner. This is aligned with the deficit model of communication, which is currently (although not unanimously) considered obsolete in the mainstream literature.

\section{Conclusion}

Our study was motivated by the need to map the research done on the increasingly important topic of PEST (Delgado et al., 2011; Loureiro and Conceição, 2019; Stilgoe et al., 2014). The focus on case studies derived from the growing criticisms that have been levelled at PEST literature relying on case studies. Critics claim that this literature has become a chaotic set of contextual case studies that might not provide comprehensible data for systemic or holistic approaches (Braun and Könninger, 2018; Chilvers et al., 2018).

We gathered a robust set of articles published between 2002 and 2017, and generated a map of the case study literature on public participation in science and technology to extract any emerging patterns that characterised the sample and that could be admitted as general trends in public participation. We used different methodologies with a particular emphasis on quantitative methods, including computational tools that facilitate the organization, analysis and visualisation of large datasets.

Our findings showed that the PEST literature using case studies was highly concentrated in native English-speaking countries, and in multidisciplinary research that mostly combined environmental studies and social sciences research. This suggests that public engagement in science and technology is not yet widespread in either a multitude of knowledge domains or globally, although it is growing. This is aligned with the argument of some scholars, such as Apostolopoulou and Pantis (2009) and Wynne (2007), that public participation in science and technology is still a scarce social phenomenon.

Despite the high contextualization of case studies, we were able to find some strong crosssectional patterns across the whole sample. Three research communities were identified, and textual analysis was conducted on the full network and also comparatively between each community. We found very small discursive variations among the three communities and assume that the reasons for this are multiple and connected. (1) The emergence of public participation in science and technology is common in developed countries, particularly in native English-speaking countries where efforts to communicate science to the public have been in place for decades. (2) It is typical of developed economies, considering the expected link between the value of science and technological advancements with potential benefits for economic competitiveness. (3) It has 
a higher incidence in countries structured on democratic regimes, with a few exceptions, such as China, which has undergone a 'hard road' to secure increasingly successful public engagement with science over the last three decades (Jia and Liu, 2014). (4) Nevertheless, policies and long-term strategies aiming to open science to the rest of society may be agents of change with a strong potential impact on the discourse and academic productivity of PEST studies.

The widespread criticism aimed at the PEST literature, particularly its reliance on case studies as a central methodology, points to a wide range of subjects. The patterns found in our analysis may be the cornerstones of participatory action but also may reveal the problems that are turning the literature into a litany of case studies. We are inclined to admit that a large part of the identified patterns reveal that deficit practices still remain a major tendency in public participation insofar as the key concept emerging from the sample is 'planning process', which denotes top-down organization on the basis of public participation. Top-down public engagement is the main structural condition of deficit practices in which the public is prone to be controlled or manipulated by stronger players (see e.g. Lezaun and Soneryd, 2007).

The frequency of the words 'planning' and 'process' may also point to the fact that the litera- ture has been over-emphasising methods and procedures of public participation. Furthermore, 'planning' and 'process' are key words in project management methodologies ('project' and 'management' are also listed in the top of the word frequency ranks in Table 4). In this context, it seems right to ask how project management methodologies and managers are equipped with tools to allow the uncertainty of bottom-up citizen agency, and how to combine top-down management with bottom-up unstructured citizen initiatives. These questions seem to lead us to a similar discussion in political science in which the concepts of governing and governance are confronted. From this we can infer that the disciplines of political science may have some answers and should be incorporated in the analysis and design of public participation processes. In addition, we suggest that new frameworks for PEST design and analysis may focus on decentralising hierarchical power and dependency relationships between agents, by building a democratic setting that allows the engagement of top-down organizations with bottom-up initiatives.

\section{Acknowledgements}

This work was supported by the Portuguese Foundation for Science and Technology. Grant: SFRH/ BD/108241/2015 


\section{References}

Adriaanse LS and Rensleigh C (2013) Web of science, scopus and google scholar a content comprehensiveness comparison. Electronic Library 31(6):727 - 744.

Akmajian A, DeMers RA, Farmer AK et al. (2010) Linguistics : An Introduction to Language and Communication. 6th ed. Cambridge, Mass., United States: MIT Press Ltd.

Allum N, Sturgis P, Tabourazi D et al. (2008) Science knowledge and attitudes across cultures: A meta-analysis. Public Understanding of Science 17: 35-54 .

Apostolopoulou E and Pantis JD (2009) Conceptual gaps in the national strategy for the implementation of the European Natura 2000 conservation policy in Greece. Biological Conservation 142: 221 - 237.

Archambault É, Campbell D, Gingras Y et al. (2009) Comparing bibliometric statistics obtained from the web of science and Scopus. Journal of the American Society for Information Science and Technology 60(7): 13201326.

Bensaude-Vincent B (2014) The politics of buzzwords at the interface of technoscience, market and society: The case of 'public engagement in science'. Public Understanding of Science 23(3): 238-253.

Besley JC, Oh SH and Nisbet M (2013) Predicting scientists' participation in public life. Public Understanding of Science 22(8): 971-987.

Bhattacharya S, Kaul A, Shilpa et al. (2015) Role of bilateral institution in influencing collaboration: case study of CEFIPRA - a bilateral S\&T institution established by India and France. Scientometrics 102: 169-194.

Blondel VD, Guillaume JL, Lambiotte R et al. (2008) Fast unfolding of communities in large networks. Journal of Statistical Mechanics: Theory and Experiment P10008.

Boyack KW, Börner K and Klavans R (2007) Mapping the structure and evolution of chemistry research. In: Proceedings of ISSI 2007 - 11th International Conference of the International Society for Scientometrics and Informetrics, 2007.

Brandes U (2001) A faster algorithm for betweenness centrality. Journal of Mathematical Sociology 25(2): 163-177.

Braun K and Könninger S (2018) From experiments to ecosystems? Reviewing public participation, scientific governance and the systemic turn. Public Understanding of Science 27(6): 674-689.

Callon M (1999) The Role of Lay People in the Production and Dissemination of Scientific Knowledge. Science Technology \& Society 4(1): 81-94.

Cass N (2006) Participatory-Deliberative Engagement : a literature review. Manchester: School of Environment and Development, Manchester University.

Castell S, Charlton A, Clemence M et al. (2014) Public Attitudes to Science 2014. Ipsos MORI: 202. Available at: https://assets.publishing.service.gov.uk/government/uploads/system/uploads/attachment_data/ file/348830/bis-14-p111-public-attitudes-to-science-2014-main.pdf. (Accessed 16.12.2020)

Chilvers J, Pallett H and Hargreaves T (2018) Ecologies of participation in socio-technical change: The case of energy system transitions. Energy Research and Social Science 42:199-210.

Chopyak J and Levesque P (2002) Public participation in science and technology decision making: Trends for the future. Technology in Society 24:155-166.

Curato N and Böker M (2016) Linking mini-publics to the deliberative system: a research agenda. Policy Sciences 49:173-190.

Davis M and Laas K (2014) "Broader Impacts" or "Responsible Research and Innovation"? A Comparison of Two Criteria for Funding Research in Science and Engineering. Science and Engineering Ethics 20(4): 963-983. 
Delgado A, Kjølberg KL and Wickson F (2011) Public engagement coming of age: From theory to practice in STS encounters with nanotechnology. Public Understanding of Science 20(6): 826-845.

Ercan SA, Hendriks CM and Boswell J (2017) Studying public deliberation after the systemic turn: The crucial role for interpretive research. Policy and politics 45(2): 195-212.

European Commission (2014) Rome Declaration on Responsible Research and Innovation in Europe. (November): 1-2.

Fortunato S and Barthélemy M (2007) Resolution limit in community detection. In: Proceedings of the National Academy of Sciences of the United States of America, Washington, DC, 104(1): 36-41.

Gago JM (1990) Manifesto para a Ciência em Portugal. Lisbon: Gradiva.

Gago JM (1991) Science in Portugal, Commission for Europalia 91. Lisbon: Imprensa Nacional Casa da Moeda.

Haberer J (1983) The American People and Science Policy: The Role of Public Attitudes in the Policy Process. By Jon D. Miller. (New York: Pergamon Press, 1983. Pp. xvii + 145. \$27.50.). American Political Science Review 78: 805-806.

Holbrook JB (2005) Assessing the science-society relation: The case of the US National Science Foundation's second merit review criterion. Technology in Society 27: 437-451.

Horta H (2018) The declining scientific wealth of Hong Kong and Singapore. Scientometrics 117: 427-447.

Horta $\mathrm{H}$ and Jung J (2014) Higher education research in Asia: An archipelago, two continents or merely atomization? Higher Education 68: 117-134.

Hyett N, Kenny A and Dickson-Swift V (2014) Methodology or method a critical review of qualitative case study reports. International Journal of Qualitative Studies on Health and Well-being 9(1): 23606.

Irwin A, Jensen TE and Jones KE (2013) The good, the bad and the perfect: Criticizing engagement practice. Social Studies of Science 43(1): 118-135.

Jasanoff S (2003) Technologies of humility: Citizen participation in governing science. Minerva 41: 223-244.

Jasanoff S (2005a) Designs on Nature : Science and Democracy in Europe and the United States. New Jersey, United States: Princeton University Press.

Jasanoff S (2005b) In the democracies of DNA: Ontological uncertainty and political order in three states. New Genetics and Society. 24(2): 139-156.

Jia H and Liu L (2014) Unbalanced progress: The hard road from science popularisation to public engagement with science in China. Public Understanding of Science 23(1): 32-37.

King DA (2004) The scientific impact of nations: what different countries get for their research spending. Nature 430: 310-316.

Lezaun J and Soneryd L (2007) Consulting citizens: Technologies of elicitation and the mobility of publics. Public Understanding of Science 16(3): 279-297.

Loureiro PM and Conceição CP (2019) Emerging patterns in the academic literature on responsible research and innovation. Technology in Society 58(May): 101148.

Macnaghten P and Chilvers J (2014) The future of science governance: Publics, policies, practices. Environment and Planning C: Government and Policy 32(3): 530-548.

Mello RA (2002) Collocation analysis: A method for conceptualizing and understanding narrative data. Qualitative Research. 2(2): 231-243.

Miller JD (1992) Toward a scientific understanding of the public understanding of science and technology. Public Understanding of Science. 1(1): 23-26. 
Mongeon P and Paul-Hus A (2016) The journal coverage of Web of Science and Scopus: a comparative analysis. Scientometrics 106: 213-228.

Mosbah-Natanson S and Gingras Y (2014) The globalization of social sciences? Evidence from a quantitative analysis of 30 years of production, collaboration and citations in the social sciences (1980-2009). Current Sociology. 62(5): 626-646.

Newman MEJ (2006) Modularity and community structure in networks. In: Skyrms B (ed) Proceedings of the National Academy of Sciences of the United States of America, Washington, DC, 2006. PNAS.

Nowotny H (2014) Engaging with the political imaginaries of science: Near misses and future targets. Public Understanding of Science 23(1): 16-20.

Owen D and Smith G (2015) Survey Article: Deliberation, Democracy, and the Systemic Turn. Journal of Political Philosophy 23(2): 213-234.

Owen R, Macnaghten P and Stilgoe J (2012) Responsible research and innovation: From science in society to science for society, with society. Science and Public Policy 39(6): 751-760.

Patrício MT, Santos P, Loureiro PM, et al. (2018) Faculty-exchange programs promoting change: motivations, experiences, and influence of participants in the Carnegie Mellon University-Portugal Faculty Exchange Program. Tertiary Education and Management 24(1): 1-18.

Rennie LJ and McClafferty TP (1996) Science centres and science learning. Studies in Science Education 27(1): 53-98. DOI: 10.1080/03057269608560078.

Rip A (2014) The past and future of RRI. Life Sciences, Society and Policy 10(1): 1-15.

Rowe G and Frewer LJ (2004) Evaluating public-participation exercises: A research agenda. Science Technology and Human Values 29(4): 512-556.

Royal Society (1985) The public understanding of science. Royal Society: 1-43. DOI: 10.1038/340011a0.

Samraj B (2005) An exploration of a genre set: Research article abstracts and introductions in two disciplines. English for Specific Purposes 24(2): 141-156.

Stahl BC (2013) Responsible research and innovation: The role of privacy in an emerging framework. Science and Public Policy 40(6): 708-716.

Stilgoe J, Lock SJ and Wilsdon J (2014) Why should we promote public engagement with science? Public Understanding of Science 23(1): 4-15.

Sturgis P and Allum N (2004) Science in society: Re-evaluating the deficit model of public attitudes. Public Understanding of Science 13(1): 55-74.

Thomas G and Durant J (1987) Why should we promote the public understanding of science? In: Shortland M (ed) Scientific Literacy Papers. Oxford: Rewly House, pp. 1-44

Trench B (2008) Towards an analytical framework of science communication models. In: Cheng D, Claessens M, Gascoigne T, Metcalfe J, Schiele B and Shi S (eds) Communicating Science in Social Contexts: New Models, New Practices. Dordrecht: Springer, pp. 119-135. DOI: 10.1007/978-1-4020-8598-7_7.

Van Noorden R (2015) Seven thousand stories capture impact of science. Nature. 518(7538): 150-1. DOI: 10.1038/518150a.

Vega-Almeida RL, Carrillo-Calvet $\mathrm{H}$ and Arencibia-Jorge R (2018) Diseases and vector: a 10 years view of scientific literature on Aedes aegypti. Scientometrics 115: 1627-1634. DOI: 10.1007/s11192-018-2650-9.

Virapongse A, Brooks S, Metcalf EC et al. (2016) A social-ecological systems approach for environmental management. Journal of Environmental Management 178: 83-91

Wynne B (1992) Public understanding of science research: New horizons or hall of mirrors? Public Understanding of Science 1(1): 37-43. 
Wynne B (2007) Public Participation in Science and Technology: Performing and Obscuring a PoliticalConceptual Category Mistake. East Asian Science, Technology and Society 1(1): 99-110.. DOI: 10.1215/ s12280-007-9004-7.

Yin RK (2014) Case study research: Design and methods (5th ed.). Thousand Oaks, CA: SAGE Publications.

Zheng T, Wang J, Wang Q et al. (2015) A bibliometric analysis of industrial wastewater research: current trends and future prospects. Scientometrics 105: 863-882.

\section{Notes}

1 The acronym 'PEST' is commonly used to refer to public engagement with science and technology. However, to enhance the participatory nature of the concept of engagement, which is fundamental to our analysis, we chose the term 'public engagement and participation in science and technology'.

2 http://tools.medialab.sciences-po.fr/table2net/

3 OECD Better Life Index http://www.oecdbetterlifeindex.org/

Global Civic Engagement Report 2016 https://www.gallup.com/195686/2016-global-civic-engagementreport.aspx

4 The research fields related data do not refer exactly to the content of the articles, but instead indicate the fields of the journals where they are published, with possible overlaps of more than one field in each journal. Nevertheless, these data provide a fair if simplified insight into the distribution of the fields of knowledge of PEST studies using case studies as the main or a core method of analysis.

5 Our word frequency queries returned the 500 most frequent words. Results on a line graph show that word count increases slowly from the bottom of the ranking and grows exponentially approximately from the 30th rank to the top. This makes interpretation of word counts in rankings under 30 problematic and perhaps not recommended. 